ASIMETRIS: JURNAL PENDIDIKAN MATEMATIKA DAN SAINS

$$
\text { p-ISSN } 2721 \text { - 8724, e-ISSN } 2722 \text { - } 0214
$$

Website Jurnal: http://journal.umuslim.ac.id/index.php/asm/

$\begin{array}{rll}\text { Info Artikel: } & \text { Direvisi pada } 13 \text { Oktober } 2021 \\ \text { Disubmit pada } 9 \text { Oktober } 2021 & \text { Diterima pada } 18 \text { Oktober } 2021 \\ \text { Direview pada } 10 \text { Oktober } 2021 & \text { Tersedia secara daring pada } 28 \text { Oktober } 2021\end{array}$

\title{
PENERAPAN MODEL PEMBELAJARAN PROBLEM BASED LEARNING UNTUK MENINGKATKAN HASIL BELAJAR MATEMATIKA SISWA
}

\author{
Husnidar ${ }^{1}$, Rahmi Hayati ${ }^{2}$ \\ 1,2 Pendidikan Matematika Universitas Almuslim Bireuen, Aceh, Indonesia \\ Alamat email: husnidar0@gmail.com
}

\begin{abstract}
ABSTRAK. Penelitian ini bertujuan untuk meningkatkan hasil belajar matematika siswa dengan menggunakan model pembelajaran Problem Based Learning (PBL) pada materi skala di kelas V SD Negeri 28 Peusangan. Penelitian ini merupakan penelitian Tindakan kelas yang telah dilaksanakan sebanyak 2 siklus. Adapun subjek yang diambil adalah seluruh siswa kelas Va SD Negeri 28 Peusangan tahun ajaran 2021/2022. Tehnik pengumpulan data pada penelitian ini adalah (a). observasi, (b). wawancara, (c). dokumentasi, dan (d). tes. Berdasarkan hasil penelitian dapat disimpulkan bahwa persentase ketuntasan belajar siswa berada pada kategori sangat baik, sehingga dapat dikatakan bahwa Problem Based Learning (PBL) ini efektif digunakan pada materi skala, hal ini ditunjukkan pada siklus 1 persentase ketuntasan belajar adalah $54 \%$ dengan nilai rata-rata 75,20 , dan pada siklus 2 meningkat menjadi 95\% dengan nilai rata-rata 82,11 Pada aktifitas siswa dan guru berdasarkan hasil observasi juga terhadap model yang digunakan peneliti yaitu Problem Based Learning (PBL) berada pada tingkat yang efektif diberikan kepada siswa,
\end{abstract}

Kata Kunci: Hasil Belajar ; Problem Based Learning

ABSTRACT. This study aims to improve students' mathematics learning outcomes by using the Problem Based Learning (PBL) learning model on scale material in class V SD Negeri 28 Peusangan. This research is a classroom action research that has been carried out in 2 cycles. The subjects taken were all class Va students at SD Negeri 28 Peusangan for the 2021/2022 academic year. Data collection techniques in this study are (a). observation, (b). interview, (c). documentation, and (d). test. Based on the results of the study, it can be locked that the percentage of student learning mastery is in a very good category, so it can be said that Problem Based Learning (PBL) is used on scale material, it is effective in cycle 1 the percentage of learning completeness is $54 \%$ with an average value. 75.20 , and in cycle 2 it increased to $95 \%$ with an average of 82.11 . In the activities of students and teachers based on observations also on the model used by researchers, namely Problem Based Learning (PBL) was at an effective level given to student.

Keyword: Learning Outcomes, Problem Based Learning

\section{PENDAHULUAN}

Pendidikan memegang peranan utama dalam kehidupan manusia, dimana pendidikan tersebut bersifat sebagai alat yang dapat memberikan pertolongan dalam menyelesaikan persoalan hidup yang dihadapi oleh manusia sebagai makhluk dengan berbagai macam permasalahan. Dengan pendidikan manusia dapat berusaha merubah dirinya menjadi makhluk lebih baik dan berguna bagi diri sendiri dan bagi orang lain. Pendidikan disini bukan hanya sebatas teori yang didapat di sekolah, namun pendidikan juga dapat diperoleh langsung dari berbagai pengalaman di lingkungan sekitar. Hal ini sesuai dengan pendapat (Syah, 2010), "Pendidikan artinya memelihara dan memberi latihan". Untuk itu supaya manusia menjadi lebih baik perlu diberikan arahan dan latihan-latihan 
dalam setiap penyelesaian permasalahan, agar apa yang mereka dapatkan dari teori di sekolah maupun dari lingkungan dapat langsung mereka aplikasikan dalam kehidupan.

Salah satu upaya agar permasalahan dapat terselesaikan adalah dengan pemberian pendidikan yang diberikan kepada anak sejak dini, agar mereka senantiasa memiliki pegangan dan arahan untuk menjalankan kehidupan dengan kecerdasan dan menjadi pribadi yang baik serta memiliki akhlak yang mulia dihadapan sesama manusia dan di hadapan Allah SWT. (Budiarti et al., 2017) yang menyatakan bahwa "Pendidikan adalah usaha sadar dan terencana untuk mewujudkan suasana belajar dan proses pembelajaran agar peserta didik secara aktif mengembangkan potensi dirinya untuk memiliki kekuatan spiritual keagamaaan, pengendalian diri, kepribadian, kecerdasan, akhlak mulia, serta ketrampilan yang diperlukan dirinya, masyarakat, bangsa, dan Negara".

Pendidikan yang diperoleh setiap anak dari orang tua di rumah, dari guru di sekolah maupun dari masyarakat di lingkungan tempat tinggal mereka akan membantu proses tumbuh kembang anak dengan sendirinya, dan dengan bimbingan dan arahan dari semua pihak mereka akan menjadi pribadi yang lebih baik. Pernyataan ini sesuai dengan yang diungkapkan oleh (Aziizu, 2015) yang menyatakan bahwa "hal yang menentukan keberhasilan pembentukan pribadi yang berkualitas tanpa mengesampingkan unsur lain dalam pendidikan adalah tergantung pada tujuan pendidikannya". Jadi Pendidikan bertujuan memberikan jalan bagi anak untuk dapat mengembangkan potensinya dengan bimbingan orang dewasa untuk menjadi berguna bagi nusa dan bangsa.

Salah satu mata pelajaran yang sangat penting bagi anak untuk mengembangkan potensi dirinya adalah mata pelajaran matematika, yang merupakan pelajaran wajib disetiap jenjang sekolah dari sekolah dasar sampai ke perguruan tinggi. Untuk itu diperlukan kesiapan yang matang dari seorang anak agar mampu menguasai pelajaran matematika. Selain di sekolah, matematika juga salah satu pelajaran yang akan diaplikasikan langsung dalam kehidupan sehari-hari, baik di rumah maupun di lingkungan tempat tinggal dengan semua tingkatan generasi.

Selain itu matematika merupakan mata pelajaran yang dibutuhkan untuk setiap bidang pekerjaan, mulai dari medis sampai pada bidang tehnik. Dan matematika juga telah ada sejak dahulu jauh sebelum kita ada, untuk itu dibutuhkan daya nalar yang tinggi agar seorang anak dapat menguasai ilmu matematika. Unsurunsur yang terdapat dalam matematika dapat mangembangkan konsep kejujuran, keselarasan, konsisten serta keselarasan dari seorang anak sehingga mereka dapat berpikir secara logis dan menjadikan mereka lebih bermutu. Dewasa ini pemerintah terus mengusahakan peningkatan mutu pendidikan di sekolah, dimana baik perbaikan mutu terhadap guru sebagai pendidik maupun terhadap siswa. Demikian halnya dengan mata pelajaran matematika juga terus diupayakan peningkatannya misalnya melalui pelatihan-pelatihan dan penilaian terhadap kinerja guru matematika. Pelatihan dan penilaian tersebut meliputi kesiapan guru dalam mengajar, seperti menyusun perangkat pembelajaran baik Rpp, LKPD, bahan ajar, evaluasi maupun persiapan media dan model pembelajaran.

Salah satu materi matematika yang dipelajari di Sekolah Dasar adalah materi Skala di kelas $\mathrm{V}$ yang mempelajari ukuran pada gambar dan ukuran yang sebenarnya. Berdasarkan hasil observasi di SD Negeri 28 Peusangan, masih banyak siswa kelas $\mathrm{V}$ yang sulit memahami materi Skala dan masih banyak siswa yang bernilai dibawah KKM, selain itu siswa masih sukar memahami ukuran atau jarak sebenarnya dari sebuah gambar di denah atau peta.

Salah satu model pembelajaran yang dapat menunjang pembelajaran disetiap mata pelajaran termasuk matematika khususnya materi skala adalah model pembelajaran Problem Based LeSarning (PBL). Karena PBL ini dilaksanakan untuk lebih mengembangkan ketrampilan berpikir kritis siswa, dan di model ini siswa diusahakan untuk lebih aktif dari pada 
seorang guru dalam menyelesaikan masalah, lebih fokus dalam penyelidikan, diskusi dan lain sebagainya pada saat pembelajaran. Hal ini sesuai dengan pendapat Glazer (Nafiah \& Suyanto, 2014) yang mengemukakan bahwa "PBL memberikan ke $\llbracket$ sempatan kepada siswa untuk mempelajari hal lebih luas yang berfokus pada mempersiapkan siswa untuk menjadi warga negara yang aktif dan bertanggung jawab".

Model pembelajaran ini dilaksanakan dengan diawali dengan pemberian masalah kontekstual kepada siswa yang bertujuan untuk merangsang mereka untuk mendalami setiap permasalahan dan menyelesaikan masalah tersebut Bersama-sama dengan anggota kelompok lain dalam tim. Hal ini sesuai dengan pendapat Ducth (Shoimin, 2014), yang mengemukakan bahwa PBL adalah model pembelajaran yang bercirikan adanya permasalahan nyata sebagai konteks untuk para peserta didik belajar berpikir kritis dan ketrampilan memecahkan masalah serta memperoleh pengetahuan.

Adapun karakteristik dari PBL itu sendiri menurut Barrow (Shoimin.A, 2014: 130) adalah: (1). Learning is Student-Centered, maksudnya proses pembelajaran lebih berfokus kepada siswa sebagai pelajar, (2). Anizing Focus for Learning, maksudnya adalah permasalahan yang disajikan kepada siswa adalah permasalahan yang autentik sehingga siswa mampu dengan mudah memahami masalah tersebut serta dapat menerapkannya dalam kehidupan profesionalnya nanti. (3). Learning Occurs in Small Group, artinya model ini mengembangkan pikiran secara kolaboratif di dalam kelompok kecildengan pemberian tugas dan penerapan tujuan yang jelas. (4). Teachers act as Facilitators, dimana guru berperan sebagai fasilitator untuk siswa dalam belajar.

Adapun Langkah-langkah dari model pembelajaran PBL menurut (Shoimin, 2014) adalah sebagi berikut:

1. Guru menjelaskan tujuan pembelajaran. Menjelaskan logistik yang dibutuhkan, memotivasi siswa terlibat dalam aktivitas pemecahan masalah yang dipilh.

2. Guru menjelaskan tujuan pembelajaran. Menjelaskan logistik yang dibutuhkan. Memotivasi siswa terlibat dalam aktivitas pemecahan masalah yang dipilih.

3. Guru membantu siswa mendefinisikan dan mengorganisasikan tugas belajar yang berhubungan dengan masalah tersebut (menetapkan topik, tugas, jadwal, dll).

4. Guru mendorong siswa untuk mengumpulkan informasi yang sesuai, eksperimen untuk mendapatkan penjelasan dan pemecahan masalah, pengumpulan data, hipotesis, dan pemecahan masalah.

5. Guru membantu siswa dalam merencanakan serta menyiapkan karya yang sesuai seperti laporan dan membantu mereka berbagai tugas dengan temannya.

6. Guru membantu siswa untuk melakukan refleksi atau evaluasi terhadap penyelidikan mereka dan proses-proses yang mereka gunakan.

Berdasarkan hasil analisa tersebut penulis menganggap bahwa model pembelajaran PBL dapat manjadi alternatif menyelesaikan permasalahan siswa di SD Negeri 28 Peusangan pada materi skala. Oleh sebab itu peneliti berusaha membuat penelitian dengan judul "Penerapan Model Pembelajaran PBL untuk Meningkatkan Hasil Belajar Matematika Siswa di SD Negeri 28 Peusangan."

\section{METODE PENELITIAN}

Penelitian ini dilaksanakan terhadap siswa kelas Va SD Negeri 28 yang berjumlah 21 orang pada semester ganjil tahun 2021/2022. Adapun jenis penelitian yang digunakan adalah jenis Penelitian Tindakan Kelas (PTK). Menurut (Arikunto, 2013) "PTK bermaksud memperbaiki situasi pembelajaran di kelas, yang merupakan inti dari kegiatan pendidikan."

Prosedur yang digunakan dalam penelitian ini terdiri dari: tahap perencanaan tindakan (plan), tahap pelaksanaan (action), 
tahap pengamatan (observation) dan tahap perenungan (reflection). Sedangkan tehnik pengumpulan data dilakukan melalui observasi, wawancara, dokumentasi, dan tes.

\section{HASIL PENELITIAN DAN PEMBAHASAN}

Sebelum pelaksanaan pembelajaran, peneliti telah memberikan tes awal kepada siswa kelas Va pada materi skala, dan diperoleh bahwa sebagian besar siswa masih bernilai tidak tuntas yaitu $30 \%$ dari 21 jumlah siswa keseluruhan. Hasil tes awal siswa digunakan oleh peneliti untuk mempermudah dalam pembentukan kelompok dalam pembelajaran model PBL. Selain itu juga untuk melihat peningkatan hasil belajar siswa setelah memperoleh pembelajaran PBL. Menurut hasil penelitian pada siklus 1 dengan pembelajaran model PBL, siswa masih banyak yang bernilai dibawah rata-rata dengan tingkat ketuntasan belajar belum sampai $65 \%$, yaitu hanya $54 \%$ dari 21 orang siswa yang belum memperoleh ketuntasan belajar. Hal ini mengakibatkan peneliti mengambil kesimpulan bahwa perlu dilakukan siklus kedua, dengan harapan dapat memperoleh hasil yang lebih bagus dan mancapai ketutasan belajar. Hal ini terbukti setelah penelitian siklus ke 2, terjadi peningkatan ketuntasan belajar siswa secara signifikan yaitu $95 \%$ siswa mencapai ketuntasan belajar menggunakan model PBL. Artinya pada siklus 1 telah mencapai ketuntasan belajar karena sesuai taraf keberhasilan tindakan yaitu $65 \%$. Adapun tahapan yang dilaksanakan pada siklus 1 dan siklus ke 2 adalah sama, hanya saja ada sedikit pengembangan tindakan pada siklus ke 2.

Adapun kriteria taraf keberhasilan Tindakan menurut pendapat (Arikunto, 2013) ditentukan sebagai berikut:

$80 \%<$ NR $\leq 100 \%$ : Kriteria sangat baik

$60 \%<\mathrm{NR} \leq 80 \%$ : Kriteria baik

$40 \%<$ NR $\leq 60 \%$ : Kriteria cukup

$20 \%<\mathrm{NR} \leq 40 \%$ : Kriteria kurang

$0 \%<$ NR $\leq 20 \%$ : Kriteria sangat kurang
Indikator kinerja keberhasilan penelitian tindakan ini adalah bila hasil belajar siswa selama proses pembelajaran tiap siklus mengalami peningkatan ditandai dengan daya serap individu minimal $65 \%$ dan ketuntasan klasikal 65\% (Arikunto, 2013). Berikut ini juga disajikan tabel nilai ketuntasan belajar siswa persiklus sebelum dan sesudah pembelajaran menggunakan model PBL.

\section{Tabel 1. Ketuntasan Hasil Belajar}

\begin{tabular}{lll}
\hline Indikator & Tes awal & $\begin{array}{l}\text { Siklus 1 } \\
\text { siklus II }\end{array}$ \\
\hline Tuntas & $30 \%$ & $54 \%$ \\
& & $95 \%$ \\
Belum & $70 \%$ & $46 \%$ \\
tuntas & & $5 \%$ \\
Jumlah & 21 & 21 \\
siswa & & 21 \\
\hline Rata-rata & 71,09 & 75,20 \\
& & 82,11 \\
\hline
\end{tabular}

Berdasarkan tabel di atas dapat kita lihat bahwa pada tes awal siswa memperoleh ketuntasan rata-rata sebesar 71,09 , sedangkan pada siklus 1 rata-rata ketuntasan belajar siswa meningkat menjadi 75,20 , dan terus meningkat setelah siklus 2 yaitu sebesar 82,11.

Selain tes juga dilaksanakan observasi terhadap siswa dan observasi terhadap guru, yang dilaksanakan oleh guru matematika dan teman sejawat. Tujuan observasi ini adalah untuk mengetahui aktivitas siswa dan aktivitas guru selama pembelajaran berlangsung, selain itu juga untuk mengetahui kesesuaian antara perencanaan yang telah dibuat oleh peneliti dengan pelaksanaan.Sedangkan wawancara pada penelitian ini dilaksanakan terhadap beberapa orang yang diambil secara heterogen sebagai sampel mewakili keseluruhan populasi. hal ini sesuai dengan pernyataan (Sugiyono, 2017) bahwa wawancara digunakan sebagai tehnik pengumpulan data apabila ingin melakukan studi pendahuluan untuk menemukan permasalahan. 
Pada tes awal yang diberikan kepada siswa sebelum memperoleh pembelajaran dengan model PBL didapatkan bahwa nilai siswa sangat rendah pada materi skala, dimana sebagian besar belum mencapai ketuntasan belajar. Soal tes awal yang diberikan peneliti di sini berbentuk soal essay tentang materi skala. Tujuan pemberian tes awal ini adalah untuk mengetahui kemampuan awal siswa sebelum menggunakan model pembelajaran PBL serta untuk mempermudah pembagian kelompok saat pembelajaran PBL. Sedangkan setelah diberikan pembelajaran dengan menggunakan model PBL, nilai siswa meningkat pada siklus 1 sebanyak $54 \%$ siswa mencapai ketuntasan belajar. Nilai tersebut tersebut belum mencapai target ketuntasan belajar, karena belum mencapai $65 \%$ siswa yang tuntas pada meteri tersebut, sehingga peneliti memutuskan membuat siklus ke 2. Pada siklus ke 2 ini menunjukkan peningkatan yang signifikan, dimana nilai ketuntasan siswa mencapai 95\%. Berdasarkan hasil pengamatan tersebut dapat disimpulkan bahwa persentase ketuntasan belajar siswa berada pada kategori sangat baik, sehingga mdapat dikatakan bahwa model PBL ini efektif digunakan pada materi skala.

Adapun pada aktifitas siswa dan guru berdasarkan hasil observasi juga terhadap model yang digunakan peneliti berada pada tingkat yang efektif diberikan kepada siswa, dimana siswa dapat menyelesaikan LKPD dengan benar dan tepat waktu, siswa juga mampu bekerja sama dalam kelompok untuk menyelesaikan permasalahan yang diberikan oleh guru, serta siswa juga antusias saat mempresentasikan hasil kerja kelompok mereka ke depan kelas. Hal ini menunjukkan beberhasilan penerapan model PBL pada siswa khususnya materi skala. Selain itu model ini juga lebih mengarahkan siswa serta memberikan kesempatan kepada siswa untuk bertanya kepada teman dan gurunya.

\section{SIMPULAN}

Berdasarkan hasil analisis data dan pembahasan dapat disimpulkan bahwa:
1. Model pembelajaran Problem Based Learning (PBL) sangat efektif digunakan pada materi skala.

2. Aktivitas siswa pada proses pembelajaran dengan menggunakan model Problem Based Learning PBL berada pada kategori baik.

3. Aktivitas guru pada proses pembelajaran dengan menggunakan model Problem Based Learning PBL juga berada pada kategori baik.

\section{DAFTAR PUSTAKA}

Arikunto, S. (2013). Dasar-Dasar Evaluasi Pendidikan. In Jakarta: Bumi Aksara.

Aziizu, B. Y. A. (2015). TUJUAN BESAR PENDIDIKAN ADALAH TINDAKAN. Prosiding Penelitian Dan Pengabdian Kepada Masyarakat, 2(2). https://doi.org/10.24198/jppm.v2i2.13540

Budiarti, A., Handhika, J., \& Kartikawati, S. (2017). PENGARUH MODEL DISCOVERY LEARNING DENGAN PENDEKATAN SCIENTIFIC BERBASIS E-BOOK PADA MATERI RANGKAIAN INDUKTOR TERHADAP HASIL BELAJAR SISWA. JUPITER (JURNAL PENDIDIKAN TEKNIK ELEKTRO), 2(2). https://doi.org/10.25273/jupiter.v2i2.1795

Nafiah, Y. N., \& Suyanto, W. (2014). PENERAPAN MODEL PROBLEM-BASED LEARNING UNTUK MENINGKATKAN KETERAMPILAN BERPIKIR KRITIS DAN HASIL BELAJAR SISWA THE APPLICATION OF THE PROBLEM-BASED LEARNING MODEL TO IMPROVE THE STUDENTS CRITICAL THINKING SKILLS AND LEARNING OUTCOMES. Jurnal Pendidikan Vokasi, 4(1).

Shoimin, A. (2014). 68 Model Pembelajaran Inovatif dalam Kurikulum 2013. In AR-RUZZ MEDIA (Issue Yogyakarta).

Sugiyono. (2017). Metode Penelitian Bisnis (Pendekatan Kuantitatif, Kualitatif, Kombinasi dan R\&DSugiyono. (2017). 
Metode Penelitian Bisnis (Pendekatan Kuantitatif, Kualitatif, Kombinasi dan R\&D). In Metodelogi Penelitian.). In Metodelogi Penelitian.
Syah, M. (2010). Psikologi Pendidikan dengan pendekatan Baru. In Psikologi Pendidikan dengan pendekatan Baru. 